\title{
Modulatory Role of Moringa Extract and Vitamin E Contra Zinc Oxide Nanoparticles-Induced Nephropathy in Male Albino Rats
}

\author{
Hani M. Abdelsalam*, Abd El-Aziz A. Diab, Mansour Zahra, Sameh Al-Dohim, Nora Hassan
}

\section{Hani M. Abdelsalam*, Abd El-Aziz A. Diab, Mansour Zahra, Sameh Al-Dohim, Nora Hassan \\ Department of Zoology, Faculty of Sci- ence, Zagazig University, Ash Sharqia Governorate, EGYPT. \\ *Correspondence}

\section{Dr. Hani M. Abdelsalam}

Department of Zoology, Faculty of Science, Zagazig University, Ash Sharqia Governorate, EGYPT.

Phone: +20 1008051012

Email: hmmsama@hotmail.com

\section{History}

- Submission Date: 28-08-2019;

- Review completed: 12-10-2019;

- Accepted Date: 09-11-2019.

DOI : 10.5530/ijcep.2019.6.4.33

\section{Copyright}

(C) 2019 Phcog.Net. This is an openaccess article distributed under the terms of the Creative Commons Attribution 4.0 International license.

\begin{abstract}
Background and Aim: The present study aims to evaluate the ameliorative effect of moringa extract and Vitamin $\mathrm{E}$ alone or their combination against Zinc Oxide $(\mathrm{ZnO})$ Nanoparticles (NPs)-induced nephrotoxicity in rats. Methods: Eighty Male albino rats divided into eight groups. The $1^{\text {st }}$ group (control) received distilled water. The $2^{\text {rd }}$ group received Moring extract. The $3^{\text {rd }}$ group was treated with Vitamin E. $4^{\text {th }}$ group was administered $\mathrm{ZnO}$ Nps and group 5 received $\mathrm{ZnO}$ Nps in combination with Moringa extract. 6 received ZnO Nps in combination of Vitamin $\mathrm{E}$. $7^{\text {th }}$ group was administered $\mathrm{ZnO}$ Nps, moringa extract and Vitamin $\mathrm{E}$. The $8^{\text {th }}$ group was given $\mathrm{ZnO}$ Nps and Silymarin. After 45 days, blood and specimens were collected and renal function test parameters [urea, creatinine, uric acid and Blood Urea Nitrogen (BUN)] and lipid profile parameters were measured. Results: The results showed that administration of $\mathrm{ZnO}$ Nps caused undesirable effects on studied biochemical parameters. The moringa and Vitamin $\mathrm{E}$ administration for 30 days subsequent to $\mathrm{ZnO}$ Nps exposure yielded significant ameliorative effects (decreased levels of renal function test parameters and lipid profile) on nearly all studied parameters and such effect found compatible with the effect caused by silymarin as a nephroprotective drug. Conclusion: The moringa extract in combination with Vitamin $\mathrm{E}$ had a significant ameliorative action on ZnO NPs induced oxidative damage and toxicity in rats. ZnO (NPs) increased urea, uric acid and creatinine, BUN, as well as decreased the lipid profile parameters. Hepatic and renal protection was maximum in the combined treatment of moringa extract in combination with Vitamin $E$ than the moringa extract or Vitamin $\mathrm{E}$ alone in the ZnO NPs intoxicated rats.

Key words: Nanoparticles, Oxidative stress, Zinc Oxide, Vitamin E, Hepatotoxicity.
\end{abstract}

\section{INTRODUCTION}

Nanotechnology is production of new materials, instruments and systems and taking their control in molecular and atomic level. ${ }^{[1]}$ The rapid growth of the nanotechnology industry has led to wide-scale production and application of engineered Nanoparticles (NPs). NPs are not only used in industry and medicine but are also increasingly used in various consumer products such as cosmetics, sunscreens and food products. ${ }^{[2]}$ Furthermore, Zinc Oxide $(\mathrm{ZnO})$ is generally considered to be a material with low toxicity, because Zinc $(\mathrm{Zn})$ is an essential trace element in the human body and is commonly present in foods added as a nutritional supplement, so $\mathrm{Zn}$ attracts little attention during assessment of toxicity of NPs. ${ }^{[3]} \mathrm{ZnO}$ is slightly soluble and can release $\mathrm{Zn}^{2+}$ ions in solution. Some researchers considered that dissolved $\mathrm{Zn}$ ions in the toxicity of $\mathrm{ZnO}$ NPs played an important role ${ }^{[4]}$ inferred that toxic effects of $\mathrm{ZnO}$ NPs on cells may be attributed to the dissolution of $\mathrm{Zn}^{2+}$ ions.

Vitamins are ideal antioxidants to increase tissue protection from oxidative stress due to their easy, effective and safe dietary administration in a large range of concentrations. ${ }^{[5]}$ One of the best vital Vitamins for the body is Vitamin E. In nature, Vitamin $\mathrm{E}$ includes eight natural fat-soluble compounds, including 4 tocopherols and 4 tocotrienols. ${ }^{[6]} \mathrm{Mo}$ ringa oleifera (M.O.) leaves is one of the herbal plants with a wide range of medicinal applicability. ${ }^{[7]}$ Moringa is an important tropical crop that is used as human food, medicine. ${ }^{[8]}$ The leaves are a source of protein, $\beta$-carotene, Vitamins (A, B, C, E, riboflavin), nicotinic acid, folic acid, pyridoxine, amino acids, minerals, various phenolic, ${ }^{[9]}$ with a known powerful antioxidant property. ${ }^{[10]}$ There are multitudes of reports available on the protective effects of M.O. extract, Vitamin E individually against various xenobiotics induced oxidative stress in experimental animals. Still to date the reports are scanty regarding the combined alleviated efficacy of M.O. extract in mixture with Vitamin E on ZnO NPs induced toxicity in rats. As well as there are some controversies over the combined administration of M.O. extract in combination with Vitamin E. In view of the above considerations, the present study was designed to evaluate the protective efficacy of M.O. extract in
Cite this article: Abdelsalam HM, Diab AEAA, Zahra M, AL-Dohim S, Hassan N. Modulatory Role of Moringa Extract and Vitamin E Zinc Oxide Nanoparticles-Induced Nephropathy in Male Albino Rats. Int J Clin Exp Physiol. 2019;6(4):122-7. 
combination with Vitamin E on ZnO NPs induced toxicity and oxidative damages in the liver of rats.

\section{MATERIALS AND METHODS}

\section{Drugs}

Zinc oxide NPs

Nanomaterials or nanostructures synthesized by a variety of techniques such as spray pyrolysis, thermal decomposition; molecular beam epitaxy, chemical vapor deposition and laser ablation purchased from sigma-Aldrich (St. Louis MO, USA). The drug was given orally in a does level of $\left(7.5 \mathrm{mg} / \mathrm{kg}\right.$, b.wt) was selected on the basis of literature. ${ }^{[1]]}$

\section{Vitamin $\mathrm{E}$}

It purchased from the local pharmacy. PHARCO Company manufactures it. Each 8 tablets were then dissolved in $100 \mathrm{ml}$ twin 80 then the drug was given orally in a dose level of $(100 \mathrm{mg} / \mathrm{kg}$ b.wt) was selected on the basis of literature. ${ }^{[12]}$

\section{Silymarin Preparation}

Silymarin obtained from "Sedeco Pharmaceutical Co-6-october city. Egypt" silymarin was liquefied in distilled water and then gave by oral gavage at dose $(150 \mathrm{mg} / \mathrm{kg})$ (each $1 \mathrm{ml}$ contains $5.6 \mathrm{mg}$ of silymarin).[13]

\section{Plant Extract: Moringa Extract}

M.O. collected from the pharmacognosy experimental farm- Pharmacy College-Zagazig University (5kg.) extracted by maceration in room temperature -3 times each times $24 \mathrm{hr}$ by $70 \%$ ethanol. The total extract was concentrated under reduce pressure. Out of the total extract $(250 \mathrm{~g}), 36 \mathrm{~g}$ was dissolved in $900 \mathrm{ml}$ of distilled water and the extract was given orally in a dose level of $\left(150 \mathrm{mg} / \mathrm{kg}\right.$ b. wt.) as reported earlier. ${ }^{[14]}$

\section{Experimental Animals}

The present study carried out at Zoology Department, Faculty of Science-Zagazig University, using (90) ninety clinically healthy mature adult male albino rats (Rattus norvegicus). The animals obtained from the Animal House of Faculty of Veterinary Medicine, Zagazig University, Their weights ranged from 200-250g each. The animals housed in standard conditions, where the animals housed in metal cages, bedded with wood shavings and kept under standard laboratory conditions of aeration and room temperature at about $25^{\circ} \mathrm{C}$. The animals allowed to free access of standard diet and water ad libitum. The animals accommodated to the laboratory conditions for two weeks before being experimented.

Experimental Design: The study was performed on 90 mature male rats (Rattus norvegicus), divided into 9 main groups; each group was consisted of 10 rats.

\section{Treatment Schedule}

I) The $\mathbf{1}^{\text {st }}$ Normal control group: Served as control group in which rats received distilled water for (45days).

II) The $2^{\text {nd }} M . O$. extract treated group: Rats treated orally with aqueous suspension of M.O. extract in a dose of $(150 \mathrm{mg} / \mathrm{kg}$. bw) daily for successive (30 days) using metallic stomach tube.

III) The $3^{\text {rd }}$ Vitamin $E$ treated group: Rats were treated orally with Vita$\mathrm{min} \mathrm{E}$ at a dose of (100mg/kg. b.wt) daily for successive (30 days) using metallic stomach tube.

IV) The $4^{\text {th }} \mathrm{ZnO}$ NPs treated group: Rats were orally administered with aqueous suspension $\mathrm{ZnO}$ NPs in a dose of $(7.5 \mathrm{mg} / \mathrm{kg}$. b.wt) daily for successive 15 days using metallic stomach tube.

V) The $5^{\text {th }} \mathbf{Z n O}$ NPs plus M.O. extract treated group: Rats were orally administered with aqueous suspension $\mathrm{ZnO}$ NPs in a dose of $(7.5 \mathrm{mg} / \mathrm{kg}$. b.wt) daily for successive 15 days then administered with aqueous M.O. extract in a dose of $(150 \mathrm{mg} / \mathrm{kg}$. b.wt) daily for successive 30 days using metallic stomach tube.

VI) The $6^{\text {th }} \mathrm{ZnO}$ NPs plus Vitamin E treated group: Rats were orally administered with aqueous suspension $\mathrm{ZnO}$ NPs in a dose of $(7.5 \mathrm{mg} /$ kg. b.wt) daily for successive 15 days then administered with Vitamin E in a dose of $(100 \mathrm{mg} / \mathrm{kg}$. b.wt) daily for successive 30 days using metallic stomach tube.

VII) The $7^{\text {th }} \mathrm{ZnO}$ NPs plus M.O. extract and Vitamin E treated group: Rats were orally administered with ZnO NPs for 15 days then treated with aqueous suspension of M.O. extract and Vitamin E daily for successive 30 days.

VIII) The $8^{\text {th }} \mathbf{Z n O}$ NPs plus Silymarin treated group: Rats were orally administered for ZnO NPs in a dose of $(7.5 \mathrm{mg} / \mathrm{kg}$. b.wt) for 15 days then treated with silymarin for 30 days.

\section{Blood Sampling}

Blood samples were collected at the end of the experiment (45 successive days) from the retro-orbital vein, which allows bleeding of the animal with minimal stress. ${ }^{[15]}$

After the last administration of the drug at the end of the experiment, individual blood samples were drawn by orbital puncture (from eye plexus) using microhematocrit capillary tubes (Lancer, Athy, CountyKildare, Republic of Ireland). Serum extracted from blood without EDTA and then serum samples were transferred into Eppendorf tubes and subsequently used for renal function tests and lipid profile.

\section{Determination of Serum Urea Concentration}

Serum urea was determined calorimetrically using Diamond kit. ${ }^{[16]}$

\section{Determination of Serum Creatinine Concentration}

Creatinine in alkaline solution reacts with Picrate to form colored complex. ${ }^{[17]}$

\section{Determination of Serum Uric Acid Concentration}

Serum uric was determined enzymatically using Biocon kit ${ }^{[18]}$ enzymatic determination of uric acid was performed according to the following reaction.

\section{Determination of Serum Blood Urea Nitrogen}

Blood urea nitrogen was determined in serum by modified urease-berthelot method, using biodiagnostic kit, according to Fawcett and Soctt. ${ }^{[19]}$

\section{Lipid Profile Parameters}

\section{Determination of Serum Triglycerides Concentration}

Serum triglycerides were determined using Biocon kit (enzymatic colorimetric determination), according to Fossati and Prencipe. ${ }^{[20]}$

\section{Determination of Serum Total Cholesterol Concentration}

Serum cholesterol was determined using Bicon Kit. ${ }^{[21]}$

Determination of Serum Total Lipid: Serum total lipids were determined using using Bicon Kit. ${ }^{[22]}$

\section{Statistical Analysis of Data}

Data were collected, arranged and reported as mean \pm standard error of mean (S.E.M) of nine groups (each group was considered as one experimental unit), summarized and then analyzed using the computer program SPSS/ version 15.0). The statistical method was one way Analysis of Variance ANOVA test (F-test) and if significant differences between means were found, Duncan's multiple range test whose significant level 
was defined as $(P<0.05)$ was used according to Snedecor and Cochran ${ }^{[23]}$ to estimate the effect of different treated groups.

\section{RESULTS}

\section{Effect of ZnO Nanoparticles $(7.5 \mathrm{mg} / \mathrm{kg})$, Moringa \\ $(150 \mathrm{mg} / \mathrm{kg})$, Vitamin E $(100 \mathrm{mg} / \mathrm{kg})$ and their Combinations on Kidney Functions}

(a) Effect of $\mathrm{ZnO}$ NPs, Moringa, Vitamin E and their combinations on Creatinine:

Table 1 showed that ZnO NPs treated group afforded highly significant increase in creatinine level as compared with normal control group. Meanwhile, ZnO NPs plus vitE and ZnO NPs plus sylimarin treated groups elucidates significant decrease in creatinine level as compared with $\mathrm{ZnO}$ NPs treated group only while they also afforded significant increase in creatinine level as compared with normal control group, but the effect was much less intense as compared with $\mathrm{ZnO}$ NPs treated group. At the same time, $\mathrm{ZnO}$ (NPs) plus M.O. and Vitamin E treated group and $\mathrm{ZnO}$ NPs plus M.O. treated groups elucidate significant decrease in creatinine level as compared with normal control groups and $\mathrm{ZnO}$ (NPs) plus M.O. and Vitamin E treated group showed the best safer treatment.

(b) Effect of ZnO NPs, Moringa, Vitamin E and their combinations on serum uric acid:

$\mathrm{ZnO}$ NPs treated group elucidate a significant increase in uric acid level as compared with normal control group, Meanwhile ZnO NPs plus moringa, ZnO NPs plus Vitamin E, ZnO NPs plus moringa and Vitamin $\mathrm{E}$ and $\mathrm{ZnO}$ NPs plus sylimarin treated groups afforded decrease in uric acid level as compared with $\mathrm{ZnO}$ NPs treated group, meanwhile they induced increase in uric acid level as compared with normal control group, but $\mathrm{ZnO}$ NPs plus M.O. show the best ameliorative effect as shown in Table 1 .

(c) Effect of ZnO NPs, Moringa, Vitamin E and their combinations on serum Urea level:

Treatment of normal rats with $\mathrm{ZnO}$ NPs exhibited a highly significant increase $(P<0.05)$ in serum urea after the end of the experiment when compared with control groups. Meanwhile, $\mathrm{ZnO}$ NPs plus M.O. and $\mathrm{ZnO}$ NPs plus sylimarin treated groups afforded significant decrease in uera level as compared with $\mathrm{ZnO}$ (NPs) treated group only while it afforded significant increase in urea level as compared with normal control group but the effect was much less intense as compared with $\mathrm{ZnO}$ (NPs) treated group. Whereas, the combination between $\mathrm{ZnO}$ (NPs) and M.O. in addition to Vitamin E treated group elucidate decrease in urea level compared with normal control groups and this was the best ameliorative effect as shown in Table 1.

(d) Effect of ZnO NPs, Moringa, Vitamin E and their combinations on serum BUN:

Table 1 illustrated that ZnO NPs treated group afforded highly significant increase in BUN level as compared with normal control group. Meanwhile, ZnO NPs plus VitE, ZnO NPs plus M.O. treated groups and $\mathrm{ZnO}$ NPs plus sylimarin elucidate significant decrease in BUN level as compared with ZnO NPs treated group only while they also afforded significant increase in BUN level as compared with normal control group, but the effect was much less intense as compared with ZnO NPs treated group. At the same time, $\mathrm{ZnO}$ (NPs) plus M.O. and Vitamin E treated group showed the best safer treatment.

Effect of ZnO Nanoparticles $(7.5 \mathrm{mg} / \mathrm{kg})$, Moringa

$(150 \mathrm{mg} / \mathrm{kg})$, Vitamin E $(100 \mathrm{mg} / \mathrm{kg})$ and their

Combinations on Lipid Profile Picture

(a) Effect of ZnO NPs, Moringa, Vitamin $\mathrm{E}$ and their combinations on serum cholesterol level:
$\mathrm{ZnO}$ NPs treated group afforded significant increase in serum cholesterol level as compared with normal control group. Meanwhile ZnO NPs plus M.O. and ZnO NPs plus Vitamin E treated groups elucidate significant decrease in cholesterol level as compared with ZnO NPs treated group but $\mathrm{ZnO}$ NPs plus sylimarin elucidate a non-significant decrease in cholesterol level as compared with ZnO NPs treated only while they also, afforded significant increase in cholesterol level as compared with normal control group, but the effect was much less intense as compared with $\mathrm{ZnO}$ NPs treated group. At the same time $\mathrm{ZnO}$ NPs plus M.O. and Vitamin E treated group elucidate significant decrease in cholesterol level as compared with normal control group and this was the best safer treatment as shown in Table 2 .

(b) Effect of ZnO NPs, Moringa, Vitamin E and their combinations on serum triglycerides level:

ZnO NPs treated group exhibited significant increase in serum triglycerides level as compared with control group. Meanwhile, $\mathrm{ZnO}$ nanopartices plus Vitamin E and ZnO NPs plus M.O. treated groups elucidated significant decrease in triglycerides level as compared with $\mathrm{ZnO}$ NPs treated group only while they also, afforded significant increase in triglycerides level as compared with normal control group, but the effect was much ameliorated as compared with $\mathrm{ZnO}$ (NPs) treated group Table 2. At the same time, $\mathrm{ZnO}$ nanoarticles plus M.O. and Vitamin E treated group elucidate non-significant increase in triglycerides level as compared with normal control group and this was the best-recorded result.

(c) Effect of ZnO NPs, Moringa, Vitamin E and their combinations on total lipid:

ZnO NPs treated group exhibited significant increase in serum total lipid level as compared with control group. Meanwhile, $\mathrm{ZnO}$ (NPs) plus Vitamin $\mathrm{E}$ and $\mathrm{ZnO}$ NPs plus M.O. treated groups elucidate significant decrease in total lipid level as compared with $\mathrm{ZnO}$ NPs treated group only while they also, afforded significant increase in total lipid level as compared with normal control group, but the effect was much ameliorated as compared with $\mathrm{ZnO}$ NPs treated group Table 2. At the same time, $\mathrm{ZnO}$ nanoarticles plus M.O. and Vitamin E treated group elucidate nonsignificant increase in total lipid level as compared with normal control group and this was the best-obtained result.

\section{DISCUSSION}

The present study was an attempt to evaluate toxicity of $\mathrm{ZnO}$ nanoparticels on some physiological and biochemical parameters and the possible ameliorative role of Moringa oleifera extract and Vitamin E (VE) in alleviating the toxicity of $\mathrm{ZnO}$ nanoparticels when given to normal rats. The toxicological effects of Zinc Oxide NPs ( $\mathrm{ZnO}-\mathrm{NPs}$ ) are attracting increasing concern as the field of nanotechnology progresses. Although the work proposes that toxicity of ZnO-NPs may be linked to their dissolution, the mechanism for $\mathrm{ZnO}$ (NPs) perturbation of cytosolic zinc concentration $\left(\left[\mathrm{Zn}^{2+}\right] \mathrm{c}\right)$ homeostasis remains unclear. There was a great toxicity of $\mathrm{ZnO} \mathrm{NPs}$ by in-vitro studies on different biological system like bacteria and mammalian cells. ${ }^{[24]}$

M.O. leaves act as a good natural source of antioxidant vitamins/compounds such as ascorbic acid, flavonoids, phenolics and carotenoids. The higher concentration of ascorbic acid, estrogenic substances and $\beta$-sitosterol, vitamins and particular essential amino acids such as methionine, cysteine, tryptophan and lysine present in M.O. leaves and pods make it virtually an ideal nutritional supplement. ${ }^{[25]}$ It possesses various biomedical properties such as anti-inflammatory, antioxidant, antimicrobial, antifertility, anticancer, antihepatotoxic and antiulcer activities. ${ }^{[26]}$

VE has a tocopherol structure. Naturally, there are various tocopherols such as alpha, beta, gamma, delta, eta and zeta. D-Alpha-tocopherol exhibits the widest natural distribution and greatest biological activity. 
Table 1: Effect of ZnO NPs (7.5 mg/kg), M.O.(150mg/kg), Vitamin E (100mg/kg) and their combinations on kidney function parameters.

\begin{tabular}{|c|c|c|c|c|}
\hline Groups & $\begin{array}{c}\text { Creatinine } \\
\mathrm{mg} / \mathrm{dl}\end{array}$ & $\begin{array}{l}\text { Urea } \\
\mathrm{mg} / \mathrm{dl}\end{array}$ & $\begin{array}{l}\text { Uric acid } \\
\mathrm{mg} / \mathrm{dl}\end{array}$ & $\begin{array}{l}\text { BUN } \\
\mathrm{mg} / \mathrm{dl}\end{array}$ \\
\hline Control & $.52 \pm .086^{\mathrm{c}}$ & $27.40 \pm .678^{\mathrm{d}}$ & $3.28 \pm .457^{\mathrm{b}}$ & $11.46 \pm .285^{\mathrm{f}}$ \\
\hline Vit. E & $.62 \pm .096^{\mathrm{b}, \mathrm{c}}$ & $34.20 \pm 3.42^{c}$ & $4.48 \pm .367^{\mathrm{a}, \mathrm{b}}$ & $15.28 \pm .305^{\mathrm{c}, \mathrm{d}}$ \\
\hline Moringa & $.46 \pm .120^{c}$ & $27.20 \pm 1.15^{\mathrm{d}}$ & $4.08 \pm .469^{\mathrm{a}, \mathrm{b}}$ & $12.66 \pm .616^{\mathrm{e}, \mathrm{f}}$ \\
\hline $\mathrm{ZnO}(\mathrm{NPs})$ & $1.64 \pm .350^{\mathrm{a}}$ & $52.80 \pm 2.92^{\mathrm{b}}$ & $6.00 \pm .301^{\mathrm{a}}$ & $20.50 \pm .707^{\mathrm{a}}$ \\
\hline $\mathrm{ZnO}(\mathrm{NPs})+$ moringa & $.880 \pm .096^{\mathrm{b}, \mathrm{c}}$ & $34.40 \pm 1.91^{\mathrm{c}}$ & $4.16 \pm .484^{\mathrm{a}, \mathrm{b}}$ & $14.50 \pm .502^{c, d}$ \\
\hline $\mathrm{ZnO}$ (NPs) +vit.E & $1.12 \pm .159^{b}$ & $41.00 \pm 1.00^{\mathrm{b}}$ & $5.40 \pm .425^{\mathrm{a}}$ & $15.00 \pm .447^{\mathrm{c}, \mathrm{d}}$ \\
\hline $\mathrm{ZnO}$ (NPs)+moringa+vit.E & $.84 \pm .081^{\mathrm{b}, \mathrm{c}}$ & $32.80 \pm 1.82^{\mathrm{c}, \mathrm{d}}$ & $4.46 \pm .317^{\mathrm{a}, \mathrm{b}}$ & $13.60 \pm .334^{\mathrm{d}, \mathrm{e}}$ \\
\hline $\mathrm{ZnO}(\mathrm{NPs})+$ sylimarin & $1.12 \pm 086^{\mathrm{b}}$ & $38.00 \pm 1.04^{b, c,}$ & $4.88 \pm 1.26^{\mathrm{a}, \mathrm{b}}$ & $15.80 \pm .988^{\mathrm{b}}$ \\
\hline
\end{tabular}

Means within the same column in each category carrying different litters are significant at $(P \leq 0.05)$ using Duncan's multiple range test, where the highest mean value has symbol (a) and decreasing in value were assigned alphabetically.

Table 2: Effect of ZnO NPs (7.5mg/kg), M.O.(150mg/kg), Vitamin E (100mg/kg)and their combinations on Lipid profile.

\begin{tabular}{cccc} 
Groups & $\begin{array}{c}\text { Total lipid } \\
\mathrm{mg} / \mathrm{dl}\end{array}$ & $\begin{array}{c}\text { Triglycerides } \\
\mathrm{mg} / \mathrm{dl}\end{array}$ & $\begin{array}{c}\text { Cholesterol } \\
\mathrm{mg} / \mathrm{dl}\end{array}$ \\
\hline Control & $201.80 \pm 2.69^{\mathrm{d}, \mathrm{e}}$ & $88.80 \pm 5.05^{\mathrm{d}}$ & $85.60 \pm 3.23^{\mathrm{cd}}$ \\
Vit. E & $204.60 \pm 6.35^{\mathrm{d}, \mathrm{e}}$ & $94.00 \pm 12.73^{\mathrm{d}}$ & $93.00 \pm 6.99^{\mathrm{c}, \mathrm{d}}$ \\
Moringa & $191.40 \pm 7.94^{\mathrm{e}}$ & $88.60 \pm 9.40^{\mathrm{d}}$ & $79.80 \pm 5.63^{\mathrm{d}}$ \\
ZnO (NPs) & $343.60 \pm 19.6^{\mathrm{a}}$ & $139.80 \pm 3.76^{\mathrm{a}}$ & $153.40 \pm 6.12^{\mathrm{a}}$ \\
ZnO (NPs)+moringa & $219.00 \pm 3.31^{\mathrm{b}, \mathrm{c}}$ & $110.60 \pm 5.06^{\mathrm{b}, \mathrm{c}, \mathrm{d}}$ & $98.80 \pm 3.02^{\mathrm{d}}$ \\
ZnO (NPs) + vit. E & $220.40 \pm 3.41^{\mathrm{b}, \mathrm{c}}$ & $127.80 \pm 5.47^{\mathrm{a}, \mathrm{b}}$ & $101.00 \pm 1.97^{\mathrm{d}}$ \\
ZnO (NPs) +moringa+ vit.E & $204.00 \pm 5.36^{\mathrm{d}, \mathrm{e}}$ & $102.00 \pm 7.81^{\mathrm{cd}}$ & $94.40 \pm 3.65^{\mathrm{cd}}$ \\
ZnO(NPs)+sylimarin & $239.20 \pm 8.21^{\mathrm{b}}$ & $136.80 \pm 9.71^{\mathrm{a}}$ & $121.80 \pm 10.06^{\mathrm{b}}$
\end{tabular}

Means within the same column in each category carrying different litters are significant at $(P \leq 0.05)$ using Duncan's multiple range test, where the highest mean value has symbol (a) and decreasing in value assigned alphabetically.

Tocopherol, which has the highest antioxidant activity, is also alpha tocopherol. Alpha tocopherol is found in tissues at different concentrations and inhibits lipid peroxidation. It is also known as a chain breaker antioxidant as it ends lipid peroxide chain reactions by breaking down lipid peroxide radicals. ${ }^{[27]}$

Data of the present study revealed that the administration of $\mathrm{ZnO}-\mathrm{NPs}$ to the normal rats afforded a highly significant increase in serum creatinine, urea, uric acid and BUN comparing with control group. These results agreed with Khorsandi et al. who stated that exposure of ZNP at low dose induced a significant elevation in blood concentration of BUN, $\mathrm{Cr}$ and uric acid. ${ }^{[28]}$ Treatment with low dose of ZNP caused a significant increase in histological changes and apoptotic index. ZNP at the high dose induced poor nephrotoxicity. The plasma measures of each of kidney markers are susceptible to any type of kidney disorder. When kidney damages, these biomarkers (which are inside the proximal cells of nephrons) release into the bloodstream. Hence, elevation concentration of them indicates proximal cells destruction. ${ }^{[29]}$

From the previous findings, we concluded that the elevation of creatinine, urea and uric acid level in serum after $\mathrm{ZnO}$-NPs administration could be attributed to fall in glomerular filtration rate. On the same bases, increasing the dose of $\mathrm{ZnO}$ NPs, the renal toxicity became more obvious where, $\mathrm{ZnO}$ NPs caused severe necrosis in the renal corpuscles with severs dilatation of the renal tubules accompanied with sloughing and degeneration of its lining epithelium and some renal tubules lining epithelium showed sever vacuolations with variable size. ${ }^{[30]} \mathrm{ZnO}$ NPs induce TNF- $\alpha$ production in tubular cells, which triggers a robust inflammatory response, further contributing to tubular cell injury and death. $\mathrm{ZnO}$ NPs also induce injury in renal vasculature, leading to ischemic tubular cell death and decreased Glomerular Filtration Rate (GFR). Together, these pathological events culminate in acute renal failure. ${ }^{[31]}$ In addition, many of the experimental studies demonstrated the depletion of renal GSH concentration and antioxidant activities in ZnO NPs-induced renal damage. ${ }^{[32]}$

Concerning the effect of Vitamin E, the present result showed that treatment with vitamin $\mathrm{E}$ after $\mathrm{ZnO}$ NPs administration had a slightly ameliorative effect $\mathrm{ZnO}$ NPs nephrototoxic effect as, it slightly decreased the level of creatinine, urea, BUN and uric acid level in serum. These results supported by Hany et al. who reported that post treatment with Vitamin E significantly reduced the elevated serum creatinine and urea levels and improved kidney histopathological pictur. ${ }^{[33]}$ Furthermore, the present study investigate that the treatment with moringa modulated the elevation of creatinine, urea, uric acid and BUN by ZnO NPs.

$\mathrm{ZnO}-\mathrm{NPs}$ treated group afforded significant increase in serum cholesterol, triglycerides and total lipids level as compared with normal control group. Meanwhile, ZnO-NPs plus M.O. and ZnO-NPs plus Vitamin E treated groups' elicited significant decrease in cholesterol, triglycerides and total lipids level as compared with $\mathrm{ZnO}-\mathrm{NPs}$ treated group only while they also afforded significant increase in cholesterol and triglyc- 
erides level as compared with normal control group, but the effect was much less intense as compared with $\mathrm{ZnO}$-NPs treated group. At the same time, $\mathrm{ZnO}$-NPs plus M.O. and Vitamin E treated group elicited non-significant increase in cholesterol, triglycerides and total lipids level as compared with normal control groups and this was the best safer treatment. The elevation in cholesterol, triglycerides and total lipids levels, herewith observed after $\mathrm{ZnO}$-NPs treatment period in full agreement with the result that obtained by Reza et al. ${ }^{[34]}$

The elevated serum cholesterol and triglycerides levels herein may be attributed to one or more of the following explanations. It was stated that, intoxication with $\mathrm{ZnO}-\mathrm{NPs}$ could cause centrilobular necrosis, which results in translocation and accumulation of fats from peripheral adipose tissue in the liver, increases hepatic synthesis of fatty acids, impaired the function of smooth endoplasmic reticulum and induce peroxisomes to catalyse $\beta$-oxidation of fatty acids converting them into Acetyl-CoA, the precursor of cholesterol biosynthesis and decreases the release of lipoproteins. ${ }^{[35]}$ In the present study the treatment with Vitamin E after $\mathrm{ZnO}$-NPs administration, reduce cholesterol and triglycerides level comparing with ZnO-NPs alone. Vitamin E, an important antioxidant in biological membrane, can neutralize free radicals. It appears that this effect is dose-dependent. ${ }^{[36]}$ It scavenges all three important types of ROS, namely superoxide anion, $\mathrm{H}_{2} \mathrm{O}_{2}$ and hydroxyl radicals. ${ }^{[37]} \mathrm{A}$ major antioxidant function of Vitamin $\mathrm{E}$ is inhibition of lipid peroxidation. ${ }^{[38]}$ Devaraj et al. (2007) showed that high-dose of alpha-tocopherol supplementation decreases biomarkers of ROS, lipid peroxidation, inflammation and carotid atherosclerosis in patients with coronary artery disease. ${ }^{[39]}$ Also, It seems apparent from the present result that, treatment with M.O. after $\mathrm{ZnO}-\mathrm{NPs}$ administration decrease cholesterol and triglycerides level comparing with $\mathrm{ZnO}-\mathrm{NPs}$ alone as silymarin. In addition, this result was in accordance with that reported by Ghasi et al. ${ }^{[40]}$ They reported that M.O. significantly decreased cholesterol and triglycerides.

M.O. possess various therapeutic properties like hypo-cholesterolemic, hypolipidemic, anti-inflammatory, anti-cancer, etc.,. ${ }^{[4]}$ The present study revealed that aqueous extract of M.O. has an ameliorative effect on lipid profile treatment with M.O. extract showed a decrease in the total cholesterol level, triglyceride. This is in accordance with previous studies which showed that M.O. leaf extract has got a profound hypolipidemic activity mostly due to its potential to control the mechanisms involved in the elimination of lipids from the body. ${ }^{[42]}$ The trends obtained in the total cholesterol and triacylglycerol concentrations in serum of male rats administered doses of the aqueous extract of M.O. might have resulted from the levels of alkaloids, saponins and flavonoids that were reported in the extract. ${ }^{[43]}$ Saponins are known to inhibit the absorption of dietary lipid in the small intestine through the formation of complexes with cholesterol in the diet. ${ }^{[44]}$ Furthermore, flavonoids are implicated in the inhibition of cholesterol biosynthesis in the liver ${ }^{[45]}$ and/ or inhibiting the production of apo B, needed for LDL-C production, transport and binding, thereby enhance the liver functions by facilitating reverse cholesterol transport and bile acid excretion. ${ }^{[46]}$ In addition, the reductions in the serum total cholesterol and triacylglycerol concentrations could be due also to 'autointoxication' or "leaky gut" ${ }^{[44]}$ or the reported level of saponins in the aqueous leaf extract. ${ }^{[43]}$ Renaud et al. reported that flavonoids enhanced the biosynthesis of HDL-C in the liver. ${ }^{[47]}$ Therefore, more cholesterol would be transported from peripheral tissues to the liver for excretion and this could be the reason for the reported trends in the serum cholesterol concentration in rats administered the M.O. extract. In addition, the trend obtained in serum LDL-C concentration is consistent with the serum cholesterol-lowering capability of the aqueous leaf extract of Moringa oleifera, which possibly enhanced reverse cholesterol transport and bile acid excretion, through the inhibition of production apo B, needed for LDL-C production, transport and binding. ${ }^{[46]}$ It seems apparent from the present result that, treatment with Vitamin $\mathrm{E}$ after ZnO-NPs administration decrease cholesterol, triglycerides and total lipids level comparing with $\mathrm{ZnO}-\mathrm{NPs}$ alone. And this result was also in accordance with that reported by Badiou et al. ${ }^{[48]}$

Vitamin E supplementation consider as a prophylactic agent for dyslipidemia in dialysis patients for the following reasons: it leads to (i) reduced ex vivo LDL oxidize ability. ${ }^{[48]}$ (ii) reduced in vivo lipid peroxidation ${ }^{[49]}$ (iii) is an effective antioxidant and has been proposed for the prevention or treatment of numerous health conditions, often based on its antioxidant properties ${ }^{[49]}$ (iv) the antioxidant reserve in dialysis patients is significantly lower than in healthy subjects ${ }^{[49]}(\mathrm{v})$ some studies suggested that abnormal lipoprotein metabolism and lipid oxidation are related to the cardiovascular disease in dialysis patients ${ }^{[50]}$ and (vi) in a few experimental and human studies it was shown that dietary Vitamin E supplementation may have positive effect on lipid profile. ${ }^{[48]}$ Atherosclerosis is an inflammatory process that is accelerated under circumstances of oxidative stress. It has been suggested that atherosclerosis might be delayed by an effective supplementation of the antioxidant system such as Vitamin E. ${ }^{[50]}$

\section{CONCLUSION}

Therefore, the results of the present study demonstrated that the moringa extract in combination with Vitamin $\mathrm{E}$ had a significant ameliorative action on $\mathrm{ZnO}$ NPs induced oxidative damage and toxicity in rats. $\mathrm{ZnO}$ (NPs) increased urea, uric acid and creatinine, BUN, as well as decreased the lipid profile parameters were increased. Further, the hepatic and renal protection was maximum in the combined treatment of moringa extract in combination with Vitamin $\mathrm{E}$ than the moringa extract or Vitamin $\mathrm{E}$ alone in the $\mathrm{ZnO}$ NPs intoxicated rats.

\section{ACKNOWLEDGEMENT}

To those who instilled in me the value of education and the rewards and opportunities it can generate to our parents, especially my Father, who supplied me with enthusiasm, support and creative insight. His critical reading of the manuscript that helped me refine the concept of this thesis, his deep interest in the topic and unfailing encouragement are highly appreciated.

\section{Author Contributions}

HA carried out the physiological, histological, biochemical and anatomical studies, participated in the sequence alignment and drafted the manuscript. AD: made the planning and supervision overall steps of processing of the research. MZ: participate in the physiological analysis and supervision of the research. SE: carried out the preparation of the chemicals and made the extraction of Origanum majorana and propolis and supervision of the research. $\mathrm{NH}$ : carried out the practical part of this research.

\section{CONFLICT OF INTEREST}

The authors declare no conflict of interest.

\section{Ethical approval and consent to participate}

All applicable international, national and/or institutional guidelines for the care and use of animals were followed and approved by Prof Dr. Abdallah Elhoot (Head of Zoology Department- Zagazig University).

\section{ABBREVIATIONS}

M.O.: Moringa oleifera; NPs: Nanoparticles; Vit.E: Vitamin E; ZnO: Zinc Oxide; BUN: Blood Urea Nitrogen.

\section{REFERENCES}

\footnotetext{
1. Paull R, Wolfe J, Hébert P, Sinkula M. Investing in nanotechnology, Nat Biotechnol. 2003:21(10):1144-7.

2. Van TKA, Goldman R. The Growing consumer exposure to nanotechnology in everyday product: Regulating innovative technologies in light of lessons from the past. Connecticut Law Review. 2011;44(2).
} 
3. Baek M, Chung HE, Yu J, Lee JA, Kim TH, Oh JM, et al. Pharmacokinetics, tissue distribution and excretion of zinc oxide nanoparticles. Int $\mathrm{J}$ Nanomed. 2012;7:3081-97.

4. Brunner TJ, Wick P, Manser P, Spohn P, Grass PN, Limbach L, et al. In vitro cytotoxicity of oxide NPs: Comparison to asbestos, silica and the effect of particle solubility. Environ Sci Technol. 2006;40(14):4374-81.

5. Kanter M, Coskun O, Armutcu F, UzYH, Kizilay G. Protective effects of Vitamin $\mathrm{C}$, alone or in combination with Vitamin $\mathrm{A}$, on endotoxin-induced oxidative renal tissue damage in rats. Tohoku J Exp Med. 2005;206(2):155-62.

6. Songthaveesin C, Saikhun J, Kitiyanant Y, Pavasuthipaisit K. Radio-protective effect of Vitamin $E$ on spermatogenesis in mice exposed to gamma-irradiation: A flow cytometric study. Asian J Androl. 2004;6(4):331-6.

7. Vinodini N, Chatterjee PK, Amemarsoofi A, Suman V, Pai SR. Evaluation of liver functions with Moringa oleifera leaf extract in cadmium induced adult Wistar albino rats. Int J Plant Anim Envir Sci. 2014;4(3):104-6.

8. Hamza AA. Ameliorative effects of Moringa oleifera Lam seed extract on liver fibrosis in rats. Food Chem Toxicol. 2010;48(1):345-55.

9. Khalafalla MM, Abdellatef E, Dafalla HM, Nassrallah AA, Aboul-Enein KM, Lightfoot DA, et al. Active principle from Moringa oleifera Lam leaves effective against two leukemias and a hepatocarcinoma. Afr J Biotechnol. 2010;9(49):8467-71.

10. Fakurazi S, Hairuszah I, Nanthini U. Moringa oleifera Lam prevents acetaminophen induced liver injury through restoration of glutathione level. Food Chem Toxicol. 2008;46(8):2611-5

11. Zhang $H$, Yang $D$, Yang $H$, Liu $H$. Effect on conception and offspring development in female parenatal rats following intratracheal instillation of nano- $\mathrm{C} / \mathrm{ZnO}$ and C-ZnO composite nanoparticles. Wei Sheng Yan Jiu. 2008;37(6):654-6.

12. Shati AA. Ameliorative effect of Vitamin $E$ on potassium dichromate-induced hepatotoxicity in rats. J King Saud Univ Sci. 2014;26(3):181-9.

13. Shimaa AS, Mohamed M, Amel MS. Curative effect of Allolobophora caliginosa extract on toxicity induced by silicon dioxide NPs in rats. Egypt J Zool. 2013;59(865):125-32.

14. Gupta R, Mathur M, Bajaj VK, Katariya P, Yadav S, Kamal R, et al. Evaluation of antidiabetic and antioxidant activity of Moringa oleifera in experimental diabetes. J Diabetes. 2012;4(2):164-71.

15. Scherners $\mathrm{S}$. The blood morphology of laboratory animals. Blackwell Scientific Publication (3rd Ed); 1967;20:22.

16. Patton $\mathrm{C}$, Crouch G. Enzymatic colorimetric determination of urea. Anal Chem. 1977; 49:464-9.

17. Henry RG. Clinical Chemistry. Chemicals and Technique. (2 ${ }^{\text {nd }}$ Ed), Harper, New York., 1974;257.

18. Trinder P. Enzymatic method for glucose determination. Ann Clin Biochem. 1969:3(6):29-30.

19. Fawcett JK, Scott JE. Arapid and precise method for the determination of uera Clin Pathol. 1960;13(2);156-03.

20. Fossati P, Prencipe L. Serum triglycerides determined colorimetrically with an enzyme that produces hydrogen peroxide. Clin Chem. 1990;6(28):2077-9.

21. Varley H, Richmond S. Practical Clinical Biochemistry, Chapter XIV determination of total, free and ester cholesterol using reaction with ferric chloride and sulfuric acid, Indian Edition. (4 ${ }^{\text {th }}$ Ed). 1976;313:317.

22. Zollner N, Kirsch K. Colorimatic method for determination of total lipids. Z Ges Exp Med. 1962;135:545-50.

23. 23. Snedecor GW, Cochran WG. Statistical Methods ( $8^{\text {th }}$ Ed), Ames lowa State University. 1982

24. Sinha R, Karan R, Sinha A, Khare SK. Interaction and nanotoxic effect of $\mathrm{ZnO}$ and $\mathrm{Ag}$ nanoparticles on mesophilic and halophilic bacterial cells. Bioresour Technol. 2011;102(2):1516-20.

25. Adejumo OE, Kolapo AL, Folarin AO. Moringa oleifera Lam. (Moringaceae) grown in Nigeria: In vitro antisickling activity on deoxygenated erythrocyte cells. J Pharm Bioallied Sci. 2012;4(2):118-22.

26. Goyal BR, Agrawal BB, Goyal RK. Phyto-pharmacology of Moringa oleifera Lam: An overview. Nat Prod Rad. 2007;6:34753.

27. Noworyta-Sokołowska K, Górska A, Gołembiowska K. LPS-induced oxidative stress and inflammatory reaction in the rat striatum. Pharmacol Rep. 2013;65(4):863-9.

28. Khorsandi L, Heidari-Moghadam A, Jozi Z. Nephrotoxic effects of low-dose zinc oxide nanoparticles in rats. J Nephropathol. 2018;7(3):158-65.

29. Palipoch S, Punsawad C. Biochemical and histological study of rat liver and kidney injury induced by cisplatin. J Toxicol Pathol. 2013;26(3):293-9.

30. Alferah MAZ. Histological Changes of Male Wistar Rats liver Following the Ingestion of Zinc Oxide Nanoparticles With special Emphasis on the Histochemi- cal Alterations. J Histol Histopathol. 2018;5(1):4.

31. Hanley C, Thurber A, Hanna C, Punnoose A, Zhang J, Wingett DG. The influences of cell type and $\mathrm{ZnO}$ nanoparticle size on immune cell cytotoxicity and cytokine induction. Nanoscale Res Letters. 2009;4(12):1409-20.

32. Hao F, Mei L, Yi-bin C. Impact of nano-ZnO particles on the antioxidant system of mice. Int J Environ Health. 2010;27(1)24-7.

33. Mehany HA, Abo-youssef AM, Ahmed LA, Arafa ES, El-Latif HA. Protective effect of Vitamin $E$ and atorvastatin against potassium dichromate-induced nephrotoxicity in rats. Beni-Suef University. J Basic Appl Sci. 2013;2(2):96-102.

34. Reza EH, Mohammad F, Leila S, Vahid YB, Somayeh B, Esmail A. Investigation the Zinc Oxide Nanoparticle's Effect on Sex Hormones and Cholesterol in Rat. Int Res J Biol Sci. 2013:2(8):54-8.

35. Reddy JK, Rao MS. Lipid metabolism and liver inflammation. II. Fatty liver disease and fatty acid oxidation. Am J Physiol Gastrointest Liver Physiol. 2006;90(5):852-8.

36. Rasool AH, Yuen KH, Yusoff K, Wong AR, Rahman AR. Dose dependent elevation of plasma tocotrienol levels and its effect on arterial compliance, plasma total antioxidant status and lipid profile in healthy humans supplemented with tocotrienol rich Vitamin E. J Nutr Sci Vitaminol. 2006;52(6):473-8.

37. Akbari A, Jelodar G, Nazifi S, Sajedianfard J. An overview of the characteristics and function of Vitamin $\mathrm{C}$ in various tissues: Relying on its antioxidant function. J Res Med Sci. 2016;18(11).

38. Dam BV, Hinsbergh VWV, Stehouwer CD, Versteilen A, Dekker H, Buytenhek $\mathrm{R}$. et al. Vitamin $\mathrm{E}$ inhibits lipid peroxidation-induced adhesion molecule expression in endothelial cells and decreases soluble cell adhesion molecules in healthy subjects. Cardiovasc Res. 2003;57(2):563-71.

39. Devaraj S, Tang R, Adams-Huet B, Harris A, Seenivasan T, DeLemos JA, et al. Effect of high-dose $\alpha$-tocopherol supplementation on biomarkers of oxidative stress and inflammation and carotid atherosclerosis in patients with coronary artery diseasew. Am J Clin Nutr. 2007;86(5):1392-8.

40. Ghasi S, Nwobodo E, Ofili JO. Hypocholesterolemic effects of crude extract of leaf of Moringa oleifera Lam in high fat diet fed wistar rats. J Ethnopharmacol. 2000;69(1):21-5.

41. Goyal BR, Agrawal BB, Goyal RK. Phyto-pharmacology of Moringa oleifera Lam: An overview. Nat Prod Rad. 2007;6:34753.

42. Ara N, Rashid M, Amran S. Comparison of Moringa oleifera Leaves Extract with Atenolol on Serum triglyceride, Serum Cholesterol, Blood glucose, heart weight, body weight in Adrenaline induced Rats. Saudi J Bio Sci. 2008;15(2): 253-8.

43. Oyewo EB, Adetutu A, Akanji MA. Repeated oral administration of aqueous leaf extract of Moringa oleifera modulated immunoactivities in male wistar rats. $J$ Nat Sci Res. 2013;3(6):2224-3186.

44. Evers BM. Small intestine. In: eds. Sabiston Textbook of Surgery. $18^{\text {th }}$ ed. St. Louis, Mo: WB Saunders; 2008;48.

45. Sinclair D, Davies MJ, Magliola C, Pivetti MV. Red wine and health benefits. J Sci Food Agric. 2001;88:206-13.

46. Turner W, Vanamala J, Leonardi T, Patil B, Murphy M, Wang N, et al. Grapefruit and its isolated Bioactive compounds on colon cancer chemoprotectants in rats. The $228^{\text {th }}$ ACS National Meeting, Philadelpia, PA. 2004;43.

47. Renaud S, Gueguen R, Siest G, Salamon R. Wine, beer and mortality in middleaged men from eastern France. Arch Intern Med. 1999;159(16):1885-70.

48. Badiou S, Cristol JP, Morena M, et al. Vitamin E supplementation increases LDL resistance to ex vivo oxidation in ahemodialysis patients. Int J Vitam Nutr Res. 2003;73(4):290-6

49. Atamer A, Kocyigit Y, Ecder SA, et al. Effect of oxidative stress on antioxidant enzyme activities, homocysteine and lipoproteins in chronic kidney disease. $J$ Nephrol. 2008; 21(6):924-30.

50. Pryor WA. Vitamin E and heart disease: Basic science to clinical intervention trials. Free Radic Biol Med. 2000;28(1):141-64 